\title{
The Case for Replacement Migration
}

"New Germans? We make them ourselves."

Population ageing is a global phenomenon. In almost all states of the world, the proportion of older persons is increasing. ${ }^{2}$ This process, which is expected to accelerate in the coming decades, alters the balance between the aggregate capacities and needs of a population, and is captured, albeit crudely, by the so-called "age dependency ratio" - i.e. the ratio of persons aged 65 or above to persons aged 20-64. As this ratio increases, transfer programs between age groups - programs that transfer resources from persons of working age to the elderly, such as public pensions, health care and long-term care - become unsustainable without reform.

This article examines the nature of the demographic policies developed states should pursue in response to population ageing. ${ }^{3}$ Demographic policies aim to affect the size or composition of a population. More specifically, I will examine the relative emphasis developed states should place on two types of demographic policy that aim at increasing the proportion of working-age persons in their populations: pronatalism, which

${ }^{1}$ Translated from a poster by the Alternativ für Deutschland (AFD) party during the 2017 German election.

${ }^{2}$ For an overview of the world's ageing population, see United Nations, Population Division, World Population Ageing 2015 (2015) (ST/ESA/SER.A/390).

${ }^{3}$ On population ageing challenges in developing states, see Norman Daniels, Just Health: Meeting Health Needs Fairly (Cambridge: Cambridge University Press, 2007), pp. 161-190. 
aims to increase the fertility rate of the population, and replacement migration, which aims to increase its immigration rate. Neither of these demographic policies, nor some combination of them, can realistically "solve" the problem of population ageing over time, at least if by that we mean rendering existing inter-age group transfer programs permanently sustainable. ${ }^{4}$ But they can form part of the overall adjustment developed states should make to population ageing.

This article defends the conclusion that developed states have a conditional duty to prioritise replacement migration over pronatalism. ${ }^{5}$ This is a conditional duty in the sense that it holds only if states decide to pursue a demographic response to population ageing. I do not assume that states must adopt a demographic response to ageing - it may well be permissible for them to adopt a purely non-demographic response. My main claim is that if they do adopt a demographic response, then they must adopt replacement migration rather than pronatalism as their preferred demographic response.

Section 1 provides background information about the demographic transition that is taking place in developed states, and defines "pronatalism" and "replacement migration". Section 2 answers the objection that an ethical comparison of different

\footnotetext{
${ }^{4}$ This point is elaborated in Section 1.

${ }^{5}$ Whether replacement migration should be given priority over pronatalism is an issue that has received almost no scholarly attention. Two related discussions are Tim Meijers, Justice in Procreation, PhD Thesis, Université Catholique de Louvain (2016), which examines whether states can consistently exclude immigrants for demographic reasons, while granting citizenship to native-born children, and Axel Gosseries and Danielle Zwarthoed, "Generations and Global Justice," Global Political Theory, eds. David Held and Pietro Maffettone (Cambridge: Polity, 2016), pp. 281-304, which provides an overview of challenges that confront replacement migration policies.
} 
demographic policies is misplaced since developed states should abstain from demographic policies altogether. Section 3 shows how the duty to select replacement migration instead of pronatalism as the preferred demographic policy follows from what I call the beneficence claim. This is the claim that states have duties not to deprive significantly worse off non-members of important benefits if they, or other groups they would thereby affect, would incur no non-negligible cost in their doing so. In particular, I show that were states to adopt pronatalism ahead of replacement migration, they would deprive would-be immigrants of significant opportunities to improve their quality of life while replacement migration would have only a negligible cost on their population and other affected groups (in particular, the population in the would-be immigrants' home states, and future people). Section 4 responds to the objection that the value of national culture overrides the conditional duty to adopt replacement migration.

\section{The Demographic Transition, Pronatalism and Replacement Migration}

The ageing of populations in almost all parts of the world is driven by the same two-step process known as the "demographic transition": declining mortality rates followed by declining fertility rates. Sustained mortality-decline first began in populations in northwest Europe around 1800, where successful public health measures (e.g. the smallpox vaccine of the late 1700s) began taking effect. By the late 1800s, these populations also began seeing a decline in their fertility rates. This demographic transition is currently underway, at different stages of advance, in virtually all populations of the world. ${ }^{6}$

Depending on where exactly a given population finds itself in the demographic transition, its age-structure will be affected in different ways. At the initial stage of

\footnotetext{
${ }^{6}$ See Ronald Lee, "The demographic transition: three centuries of fundamental change," Journal of Economic Perspectives 17 (2003), 167-190.
} 
demographic transition, when there is mortality decline, but as yet no fertility decline, there is a relative increase in the number of surviving children in a given population (because mortality declines most at the youngest ages). Once fertility rates also begin to decline, the age groups that grow the fastest, to begin with, are the working age-groups. This second phase has thus been called the "demographic dividend". In a third phase, once both mortality and fertility rates have been declining for a significant period, the proportion of elderly persons begins to rise. Developed states are currently in the third phase of democratic transition. In the European Union between 1965 and 2015, the ratio of persons aged above 65 and over, to persons aged between 20-64, increased from an average of $15 \%$ to $29 \%$. The 2015 figures for the United States and Canada are $22 \%$ and $24 \%$, respectively, while, in Japan, the 2015 ratio stood at $43 \%{ }^{7}$

Broadly speaking, states can pursue two kinds of policies in order to adjust to the growing needs of their ageing populations. Non-demographic policies adapt a given population to its increasing age dependency ratio without altering the proportions of its different age groups. For example, states have sought to raise the retirement age in order to simultaneously increase the amount of work and decrease the amount of retirement in the economy. ${ }^{8}$ Alternatively, states can pursue demographic policies, which aim to alter the age-structure of the population. I will compare two demographic policies:

(i) Pronatalist policies. The pronatalist policies I consider are restricted to policies that encourage people to have more children, in particular through economic incentives

\footnotetext{
${ }^{7}$ See World Bank, Age Dependency Ratio
} http://data.worldbank.org/indicator/SP.POP.DPND?view=chart (accessed on 3 July 2017) ${ }^{8}$ Around half of OECD states now automatically adjust their state pensions to changes in life expectancy. See OECD, Pensions at a Glance 2011 (Paris: OECD Publishing, 2011), pp. 81-102. 
(e.g. child allowances) and information campaigns that promote parenthood. Examples of such policies range from the historically influential 1939 Code de la Famille in France, which offered payments to families with a third child, ${ }^{9}$ to more colourful, present-day policies such as the annual "Day of Conception", a public holiday on September 12 in the Russian city, Ulyanovsk, during which couples can attempt to win a prize by giving birth to a child exactly nine months hence. ${ }^{10}$ I leave aside pronatalist policies that violate basic rights, such as, arguably, policies that criminalise abortion (e.g., under the Ceausecu regime in Romania between 1967-1989).

(ii) Replacement migration. The term "replacement migration" was first coined in a report issued by the UN in $2001 .^{11}$ Its meaning is open-ended because there is more than one way we can construe the relevant deficit that replacement immigration is meant to replace. The UN report estimated the amounts of net migration that a group of low-fertility developed states would need during the period to 2050 in order to make up for several kinds of deficits. One deficit it considered was in a state's population size relative to some stipulated size. Another deficit it considered, which is more relevant for our discussion, is in a state's potential support ratio relative to its 1995 potential support ratio (the potential support ratio is the inverse ratio to the age dependency ratio). The number of net immigrants that low fertility states need in order to keep their potential support ratios at their 1995 levels is extremely large. Germany, for example, would need approximately 188 million net migrants in the period to 2050 - on average, 3.5 million net migrants per

\footnotetext{
${ }^{9}$ See Sarah Howard, "France," Families and States in Western Europe, ed. Quentin Skinner, (Cambridge: Cambridge University Press, 2011), pp. 42-67.

${ }^{10}$ See "Russians given day off to make babies," The Guardian, September 12, 2007.

${ }^{11}$ United Nations, Population Division, Replacement Migration (2001)
}

(ST/ESA/SER.A/206). 
year. The UN report estimates that Germany's population size in 2050 would have to reach an astronomical 299 million people if it is to keep its 1995 potential support ratio constant. ${ }^{12}$ The general lesson in these numbers, as demographers have known for some time, is that the only way replacement migration (or any demographic policy) can keep the potential support ratio constant during the third phase of demographic transition is by growing the population size unsustainably. Clearly, demographic policy - be it replacement migration or pronatalism - cannot render population ageing economically sustainable on its own. ${ }^{13}$

This article construes replacement migration policy as any policy that aims to increase the net immigration rate of working-age members of the population. Two more specific points should be noted about the notion of a "replacement migration" policy. First, I assume that replacement migration policies aim to admit working-age foreigners who are not asylum-seekers or refugees. Replacement migration policies consist, for example, of policies that reduce the number of points necessary for entry (assuming a points-based immigration system) or relaxing the constraints on employers to hire foreign workers (assuming an employer-based immigration system). I make this assumption because I want to examine whether states must give priority to replacement migration over pronatalism even when the would-be immigrants do not need safe harbour from human rights violations they would suffer in their home states. ${ }^{14}$ Secondly, replacement migration

${ }^{12} \mathrm{UN}$, Replacement Migration, p. 27.

${ }^{13}$ See David Coleman, "Replacement Migration, or why everyone is going to have to live in Korea," Philosophical Transactions of the Royal Society 357 (2002): 583-598.

${ }^{14}$ Note that the beneficence claim on which I will base my case for replacement migration is distinct from this safe harbour claim - i.e. the claim that states must give safe harbour to people who would suffer human rights violations in their home states. In contrast to the 
policies can differ from each other in terms of their specific provisions. The skills that immigrants must have in order to gain entry, their age, and their right to bring relatives with them to the host state, are the three most salient provisions (given the aim of rendering population ageing economically sustainable). ${ }^{15}$ My central claim in this article is not that developed states are morally obliged to give priority to every possible replacement migration policy over pronatalism, but to some forms of replacement migration policy (I say which below).

\section{Why Demographic Policy At All?}

Before defending the priority of replacement migration, I first consider the preliminary objection that an assessment of demographic responses to populating ageing is misplaced. This objection appeals to environmental considerations and proceeds in two steps. First, any demographic policy of a developed state has the effect of increasing its population size and therefore also its overall carbon emissions. ${ }^{16}$ This exacerbates the risk of climate

safe harbour claim, the beneficence claim can apply even when would-be immigrants do not suffer human rights violations in their home state, and, in contrast to the beneficence claim, the safe harbour claim applies even if admitting asylum seekers or refugees would come at non-negligible cost to the home state.

${ }^{15}$ As Gosseries and Zwarthoed point out, an age criterion for admission is particularly important if replacement migration is to help tackle the problem of population ageing. Such criteria form part of the Australian, Canadian and British points based immigration systems. See, “Generations and Global Justice,” p. 295.

${ }^{16}$ For the environmental case against immigration to the United States that generalizes to other developed states, see Phillip Cafaro and Winthrop Staples III, "The environmental 
change that will either set back the interests of future people, or increase the need for other policies that reduce emissions or ameliorate their environmental impact. Secondly, the ageing-induced problem of unsustainable inter-age group transfer programs can, in any case, be addressed if developed states focus their attention on non-demographic policies, such as raising the retirement age. Demographic policies are therefore unnecessary, and hence unjustified, given their higher carbon footprint. ${ }^{17}$

The environmental case against demographic policy is not a conclusive basis for us to abstain from considering whether one demographic policy should be prioritised over another. There are a number of reasons for this. First, relying exclusively on a nondemographic policy response to population ageing isn't cost-free for current generations. Crudely put, if demographic policy isn't used to add extra workers to the workforce, then either existing workers will have to do more work, or existing elderly recipients of their contributions will have to make do with fewer contributions (raising the retirement age does a bit of both). Secondly, it needs to be remembered that all developed states - bar Israel, Mexico and Turkey - are currently experiencing below-replacement fertility rates. ${ }^{18}$ So our context is one in which demographic policy will not necessarily increase population size in developed states but only prevent it from declining at a faster rate than

argument for reducing immigration into the United States," Environmental Ethics 31 (2009), 5-30.

${ }^{17}$ For a defense of population decline that uses the two-step argument, see Robert Goodin, “The breeder's welfare state: a cautionary note," Arguing About Justice: Essays for Philippe Van Parijs, eds. Axel Gosseries and Philippe Vanderborght (Louvain: Presses Universitaire de Louvain, 2011), pp. 237-244.

${ }^{18}$ See OECD Family Database http://www.oecd.org/els/family/database.htm (accessed on 4 July 2017). 
otherwise. Thirdly, current generations in developed states may be able to pursue other policies that help to offset the environmental impact of a demographic policy- e.g. by investing in green technology and by increasing their support for the pursuit of a sustainable development goals that will reduce the fertility rate in developing states (e.g. the universal provision of primary and secondary education, and family planning services). ${ }^{19}$ Finally, it may be useful to know how states must prioritize between a set of policy responses to a given problem other than the policy that is best from a normative point of view. This is because states sometimes prefer not to do what is best from a normative point of view. Thus, even if, states should ideally abstain from demographic policy altogether, we may still need to know whether we should recommend their giving priority to pronatalism or replacement migration as their preferred demographic response to ageing.

\section{Four Perspectives on Replacement Migration}

My case for the priority of replacement migration focuses on the relative impact of replacement migration and pronatalism on four affected groups: (a) The host state - i.e. the state that is considering whether to adopt a replacement migration policy, (b) would-be immigrants - i.e. the persons who would emigrate to the host state if it adopted a replacement migration policy, (c) the home state - i.e. the state from which the would-be immigrants would emigrate, and (d) future people - people who will exist in the future (in

${ }^{19}$ For the claim that the pursuit of the sustainable development goals approved by the UN General Assembly in September 2015 will lower the size of the world population by 2100 relative to projections made by the Intergovernmental Panel on Climate Change, see Guy J. Abel. et. al., "Meeting the sustainable development goals leads to lower world population growth," Proceedings of the National Academy of Sciences 113 (2016). 
the host state, the home state and other states). ${ }^{20}$ I will argue that were developed states to prioritise replacement migration ahead of pronatalism, would-be immigrants would stand to benefit to a significant degree, while the other three groups would incur no negligible costs. Thus, if we endorse the beneficence claim - i.e. that a state has a duty to adopt policies that provide significantly worse off non-members with important benefits if its current population, or other potentially affected groups, would incur no non-negligible costs as a result - we must conclude that states have a duty to prioritise replacement migration ahead of pronatalism as their preferred form of demographic response to ageing.

A key strength of this case for replacement migration is that the beneficence claim can be upheld from within two foundational approaches to normative theorising: a contractualist approach and an aggregative approach (that emphasises one or another social welfare function, e.g. utilitarianism or prioritarianism). Very roughly, contractualism tells us to compare individual objections to the policies under consideration and to reject the policy that faces the strongest individual objection. ${ }^{21}$ Aggregative approaches tell us to reject the policy that promotes the smallest sum, or

\footnotetext{
${ }^{20}$ I assume that the policy choice will not affect other groups of persons to a degree that is sufficiently significant to justify altering the conclusion we would reach were we to consider its impact only on groups (a)-(d).

${ }^{21}$ On contractualism, see T. M. Scanlon, What We Owe to Each Other (Cambridge, MA: Harvard University Press, 2000); and for an application of contractualism to global justice, see Pablo Gilabert, From Global Poverty to Global Equality (Cambridge: Cambridge University Press, 2012), especially Ch. 2.
} 
weighted sum, of welfare (according to one or another social welfare function) ${ }^{22}$ Both foundational approaches converge on the beneficence claim (it is true both that the failure to comply with the beneficence claim would raise the strongest individual objection and that complying with the beneficence claim would produce the greatest sum of welfare). Thus, assuming that the beneficence claim entails that developed states must give priority to replacement migration, proponents of either foundational approach to normative theorising should endorse a duty to prioritise replacement migration. ${ }^{23}$

One possible concern with appealing to the beneficence claim in order to justify a duty to prioritise replacement migration, is that while beneficence is often invoked in discussions of the duties of individuals, it is not often invoked in discussions of the duties of states. ${ }^{24}$ However, we can plausibly construe the beneficence claim as it applies to a

${ }^{22}$ On the various social welfare functions that might be used in an aggregative approach to policy evaluation, see Matthew Adler, Well-Being and Fair Distribution, (Oxford: Oxford University Press, 2016), especially Ch. 2.

${ }^{23}$ The beneficence claim also sidesteps ongoing debates in global justice over the extent to which states must minimize economic inequality between themselves and non-members and the extent to which they may adopt a libertarian stance towards non-members. All but the staunchest global libertarian should be able to endorse the beneficence claim. For an overview of the global justice egalitarianism literature, see Christian Barry and Laura Valentini, "Egalitarian challenges to global egalitarianism," Review of International Studies 35 (2009), 485-512.

${ }^{24}$ Normative political theorists do often refer to the idea that states have "positive duties" to provide non-members with basic necessities, e.g. food, but this isn't the same as the beneficence claim, which says that states must benefit non-members when it is relatively costless for them to do so. 
state as nothing other than a set of beneficence claims that apply to its individual members. To assert a beneficence claim about a state is, in other words, to assert that there exists a set of beneficence claims that apply to its individual members that generate duties for them to combine their actions with each other in order to collectively benefit nonmembers, assuming that their so combining their actions is relatively costless for them.

(i) Would-be immigrants. We can begin by briefly noting the relatively straightforward point that replacement migration would be preferable to pronatalist policy from the perspective of would-be immigrants under virtually all realistic circumstances. Replacement migration provides would-be immigrants with a valuable opportunity to emigrate in search of a better life. There may be extreme forms of replacement migration in which immigrants would be deprived of basic rights in their host states, but this is not an unavoidable feature of a replacement migration policy, and it is difficult to believe that this would actually be a feature of replacement migration in most developed states.

(ii) Future people. In determining how we should take the interests of future people into account in our evaluation of pronatalism and replacement migration, we encounter two deep questions in population ethics. The first question is about the relevance of the fact that the future people that would exist under prontalism are not the same as the future people that would exist under replacement migration. Does this fact of non-identity between the future people that would exist under either policy imply that we may disregard the interests of future people from our evaluation of the two policies? This implication may seem to follow from this fact: it would be true of whichever policy we chose that the future people that would exist under it could not have been made better off had we chosen the other policy instead. ${ }^{25}$ The second question is whether our comparison

\footnotetext{
${ }^{25}$ For the source of the "non-identity problem" - that future people may be unable to raise objections against policies that affect their interests, see Derek Parfit, Reasons and
} 
of pronatalism and replacement migration should take into account the fact that one policy might bring more people into existence with lives worth living than the other policy. This second question asks about the relevance of these extra potential people to our policy choices. Should the interests of extra potential people matter in our evaluation of policies?

The case I will make for replacement migration is robust with respect to how we answer the first question about non-identity. To see this, suppose, on the one hand, that we accept that the non-identity of the future people that would exist under pronatalism and replacement migration implies that we may disregard their interests. In that case, we should evaluate pronatalism versus replacement migration only by comparing the three other perspectives I have distinguished, and, as I show below, the beneficence claim tells in favour of replacement migration when we compare only those three perspectives. Suppose, on the other hand, we deny that non-identity implies that we may disregard the interests of future people. In that case, we should reach the same conclusion, because, as I will argue below, it is unlikely that replacement migration will be worse for future people than pronatalism.

My case for replacement migration is not robust, however, with respect to how we answer the second question about potential people. It is likely that pronatalism will bring more people into existence than replacement migration. So, if we had to take into account

Persons, (Oxford: Oxford University Press, 1986), pp. 351-380. The non-identity is particularly serious for the contractualist approach to normative theorising because of its commitment to the so-called "impersonalist restriction" - its claim that we must exclude considerations about impersonal goodness or badness when determining whether we should reject a given policy. For an important attempt at showing how contractualism can address the non-identity problem despite its adherence to the impersonalist restriction, see Rahul Kumar, "Who can be wronged?" Philosophy \& Public Affairs 31 (2003), 99-118. 
the interests that potential people have in coming into existence, the case for replacement migration would be weakened. The case for replacement migration may thus need to assume that we do not have reason to bring potential people (with lives worth living) into existence. This assumption is not without difficulties and has been the subject of much controversy within population ethics. ${ }^{26}$ It should be noted, however, that the assumption that we do not have reason to bring potential people into existence aligns with commonsense: most people do not believe that we owe existence to potential people, or that we have impersonal reasons to bring further potential people into existence beyond those that would, in any case, come into existence (at least if a large enough future population is already secured).

We can now proceed to distinguish between two main pathways through which the policy choice between replacement migration and pronatalism will affect the interests of future people. The first is via its economic impact, the second is via its environmental impact. Let me explain how I will discuss each kind of impact.

When it comes to the economic impact of both types of demographic policy on future people, I will make the following simplifying assumption. If replacement migration has better economic consequences than pronatalist policy for currently alive people, I assume it will have at least no worse economic consequences than pronatalist policies for future people with one exception. This exception is the case in which replacement migration achieves its better economic consequences for currently alive people by using up resources that would otherwise have been available to future people For example, if currently alive people in the host state obtain their greater economic gains from replacement migration through extensive public borrowing (say, in order to fund the

\footnotetext{
${ }^{26}$ These difficulties are discussed in Jeff McMahan, "Problems of Population Theory,"
} Ethics 92 (1981): 96-127. 
integration of immigrants) then we cannot confidently say that the good economic consequences replacement migration has for currently alive people translates into good economic consequences for future people in the host state. This simplifying assumption makes our discussion of the economic impact of the choice between replacement migration and pronatalism on future people easier, because it allows us to determine that impact only by looking at its impact on the current alive people in the host state. Since I will discuss the economic impact of the two demographic policies on the currently alive people in the host state in sub-section (iii) below, I will postpone a conclusion about its economic impact on future people for now and return to this in the concluding paragraph of this section.

For the moment, we can proceed to compare the environmental impact of the choice between replacement migration and pronatalism on future people. Here it is helpful to observe that while both policies add persons to the working-age populations of the host state, replacement migration, unlike pronatalism, simultaneously subtracts those persons from the working-age populations of the home states they leave behind. For every working-age person added by a pronatalist policy, the increase in carbon emissions (relative to no demographic policy) is (a) the emissions produced by an average-length life lived in a developed state. By contrast, for every working-age person added by a replacement migration policy, the equivalent increase in emissions is (b) the emissions produced by an adult-portion of an average-length life in the host state minus the emissions of an adult-portion of an average-length life in the state the immigrant leaves 
behind. Given that (b) is almost always lower than (a), we have good reason to believe that replacement migration has better environmental consequences than pronatalism. ${ }^{27}$

One complication for this conclusion arises from the fact that immigrants tend to have higher fertility rates than native-born adults. ${ }^{28}$ This means that the number of second generation persons added by a replacement migration policy is likely to be higher than the number of second generation persons added by a pronatalism policy, at least if we assume that both policies introduce the same number of first generation adults, and this could mean that replacement migration will produce higher emissions than pronatalism in the long run.

Note, however, that the number of first generation persons added by a replacement migration policy can be adjusted downwards in light of the higher average fertility rates of immigrants, so that the total increase in population over two generations (and subsequently) that is caused by replacement migration is equivalent to the same increase that would be caused by pronatalist policy. Of course, this downwards adjustment will mean that replacement migration does not have as significant an initial impact as pronatalism would have on altering the relative sizes of the age groups in the host state. But replacement migration will eventually make up for that due to the higher average fertility rates of immigrants and the subsequently larger group of second generation persons it adds. The point is illustrated in Table 1.

${ }^{27}$ Replacement migration may increase emissions relative to no demographic policy, but recall that we are not comparing replacement migration with the absence of demographic policy, but with pronatalism.

${ }^{28}$ For a discussion of the higher average fertility rates of immigrants see Tomas Sobotka, "The rising importance of migrants for childbearing in Europe," Demographic Research 19 (2008), especially 236-238. 
Table 1: Pronatalism and replacement migration over two generations

1st Gen Fertility Rate 2nd Gen Total

$\begin{array}{lcccc}\text { Pronatalism } & 200 & 1.8 & 360 & 560 \\ \text { Repl. Migration } & 160 & 2.5 & 400 & 560\end{array}$

If a pronatalism were to introduce 200 persons and a replacement migration 160 persons, and we assume average fertility rates of 1.8 and 2.5 , respectively for each group, the number of persons each policy contributes over two generations is the same (560). But replacement migration will have a smaller environmental impact given that many of the 160 persons it adds in its first generation will have lived the first portions of their lives in lower-emitting, developing states.

Two further points diminish the environmental concerns we should have about replacement migration relative to pronatalism. First, we should not assume that the difference in average fertility rates between immigrants and native-born adults is fixed across all background social policies adopted in the host state. It is feasible for the host state to adopt background policies that help immigrants adapt to local norms and this may have the effect of decreasing the difference between their fertility rates and those of native-born adults. Secondly, replacement migration may reduce the number of children that immigrants have in comparison to the number they would have had had they remained in their home states.

In sum, there are significant immediate savings in emissions if a person is added to the population of developed states via immigration rather than by his being brought into existence via a pronatalism policy. There are also, to be sure, eventual costs in emissions to the extent that persons added via immigration may increase the average fertility rate in that society, but these can be avoided if the replacement migration policy adjusts the 
number of persons it introduces downwards. These considerations make it reasonable to conclude that the environmental impact of replacement migration on future people may not be worse than the environmental impact of pronatalism in a significant range of cases. Assuming the same about the economic impact of that policy choice on future people (a point I make at the end of this section), we should conclude that future people would have no significant objections to the priority of replacement migration over pronatalism.

(iii) The population of the host state. When comparing the economic impact of replacement migration and pronatalism on the current population of the host state, we face the theoretical problem that the economic effects of these two policies depend on how they interact with other economic policies - in particular, with background fiscal policies that tax and redistribute income and wealth. We must decide whether we should compare the economic effects that the two demographic policies would have on the assumption that they would be interacting with the fiscal policies that are currently in force or with alternative fiscal policies that could be in force. Consider, for example, the controversy over the effects of pro-immigration policy on low-wage native workers. ${ }^{29}$ If one analyses those effects on the assumption that background fiscal policies remain as they are, and those fiscal policies do not significantly redistribute the aggregate benefits that a proimmigration policy brings to the economy, the conclusion may well be that a proimmigration policy would have negative effects on low-wage workers. But if one asks what the effects of a pro-immigration policy would be under alternative fiscal policies that

${ }^{29}$ For a defence of the claim that immigration has negative economic effects on low-wage workers, see George J. Borjas, Heaven's Door: Immigration Policy and the American Economy (Princeton: Princeton University Press, 1999), pp. 87-104. For a critique of this claim, see David Card, "Is the new immigration really so bad?" The Economic Journal 115 (2005), 300-323. 
redistributed its aggregate benefits, the answer may be that it would have positive effects on low-wage workers (assuming these workers gain from the redistribution of those aggregate benefits).

Whether we should compare demographic policies as they interact with the fiscal policies that are currently in force or with those that could be in force depends on the underlying aim of our inquiry. My aim is to identify the demographic policy that belongs to the most defensible total set of feasible policies. ${ }^{30}$ Given this aim, we must compare how replacement migration and pronatalism interact with fiscal policies that could be in place. We can do this by asking how these policies differ in terms of the fiscally redistributable economic gains they produce for the host population (i.e. gains that can be redistributed, via feasible fiscal policies, across different social positions within the population). If replacement migration produces a no smaller amount of fiscally redistributable economic gains than pronatalism, I assume the host population can have no significant objection to it, so far as its economic effects are concerned.

This comparison of fiscal impact turns largely on two key issues: (a) the difference between the costs that the host population must undertake in order to acquire the added

${ }^{30}$ To be clear, I do not believe that the different aim of identifying what would be the most defensible demographic policy given current, and possibly unjust, fiscal policies, is without value. Knowing this is valuable for actors who are unable to alter the fiscal policies of their state in a more just direction (e.g. members of a temporary minority who favour just fiscal policies). My reason for identifying the demographic policy that belongs to the most defensible total set of feasible policies is that I believe citizens in developed states are not permanently disabled from bringing about the most defensible combination of demographic and fiscal policies, and can therefore benefit from knowing what that combination is. 
human capital of a worker introduced by replacement migration versus pronatalism, and (b) the difference in the value of the human capital added by either policy. Let us consider (a) and (b) first in a deliberately simple manner, before complicating our analysis. ${ }^{31}$ Call an average adult added to the working-age population by pronatalism, Nora, and an average adult added by replacement migration, Matilda. The host state would incur two costs in adding Nora that it would not incur in adding Matilda: (i) the cost of the incentives that the pronatalism policy would have to give Nora's parents in order for them to want to have Nora and (ii) the cost of public services consumed by Nora during her childhood (e.g. public primary and secondary education). However, taxpayers may have to cover a distinctive cost with respect to Matilda, namely (iii) the cost of effectively integrating Matilda into the workforce, e.g. providing Matilda with language instruction (though the cost of effective integration will vary depending on the type of immigrant Matilda is). There is good reason, I assume, to believe that costs (i) and (ii), taken together, are higher than cost (iii), for at least some types of immigrant. ${ }^{32}$

${ }^{31}$ While there is an extensive economics literature on the net fiscal impact of immigration on developed states, no scholarly comparison of the fiscal impact of adding native-born adults via pronatalism versus replacement migration exists so far as I am aware. The comparison that follows is intended only as a provisional analysis.

${ }^{32}$ This claim is supported by the following observation. Average annual public expenditure on primary and secondary education in OECD states is $\$ 9,258$ and each native-born needs 12 years of such expenditure (a total of \$111,096). Add expenditure on pre-school care, and healthcare, and other social policies devoted to rearing children, and the figure becomes higher. It is implausible that the effective integration of skilled immigrants into the labour market would require public expenditure anywhere near that amount. See OECD, Education Spending (Indicator), doi: 10.1787/ca274bac-en (accessed 
Next, consider the value of the human capital added by Nora and Matilda. Here it is worth observing that a replacement migration policy can make it a condition for Matilda's admission that she possesses valuable human capital, whereas no such criterion can be imposed on Nora (who will have a right to stay in her host state regardless). Once again, the difference in value between Matilda's and Nora's human capital will depend on the type of immigrant that Matilda is (replacement migration will admit more valuable human capital the more demanding its skills-based admissions criteria). So far, then, our simple comparison of the fiscal impact of Nora and Matilda supports the provisional conclusion that there will be a class of Matildas whose average member generates a greater fiscal contribution than the average Nora.

Let us now take on board some complications. First, suppose Matilda has a higher fertility rate than Nora. More public expenditure will thus be needed to cover the needs of Matilda's children than Nora's children. It might be thought that this adds costs to admitting Matilda. Here, however, we must avoid the mistake of assessing the fiscal impact of Matilda's children (and hence of admitting Matilda) by considering only public expenditure on their needs during their childhood. What we need to consider is the lifetime fiscal impact of Matilda's children and there is no reason to assume that Matilda's children won't be net fiscal contributors over their lifetimes, or that they will contribute less, over their lifetimes, than Nora's children (though, again, this will depend on the extent to which Matilda is highly skilled and able to help her children develop their human on 4 September 2017). For a review of the costs of rearing children, see Nancy Folbre, Valuing Children (Cambridge, MA: Harvard University Press, 2008). For a guide on assessing public expenditure on immigrants, see Solon Ardittis and Frank Laczko (eds.), Assessing the Costs and Impact of Migration Policy (Geneva: International Organization for Migration, 2008). 
capital). While the higher fertility rates of immigrants are indeed a matter of environmental concern (as we saw earlier), they are not necessarily a concern from an economic point of view once we adopt a lifetime view of the fiscal impact of children.

A second complication is that Nora is likely to be younger than Matilda. All Noras enter the working-age population at 18 , whereas the age of the average Matilda is much higher. Nora will thus be able to contribute more years of taxation than Matilda to the public purse. However, we should be careful not to overstate the relevance of the age difference between Nora and Matilda. Nora will indeed work for a larger number of years than Matilda, but these will be her lowest income years (e.g. 18 to 30), and she will incur public expenditure during those years. Her net fiscal contribution during the period of adulthood that precedes Matilda's admission may not even be positive. According to the Tax Foundation, the largest think-tank devoted to research on US tax policy, "households aged 35 to 64 pay more in taxes than they receive in government spending, while households under age 35 and over age 64 receive more government spending than they pay in taxes." 33

A final complication is that Matilda may bring relatives with her, whereas Nora will not, and Matilda's relatives may well end up constituting a relative cost in admitting Matilda's human capital. How extensive this cost is depends on how many relatives Matilda brings with her (and hence on how strict the family unification provision of the replacement migration is). If Matilda may only bring a spouse, he may not prove to be a net fiscal cost if he is effectively integrated into the labour market.

\footnotetext{
${ }^{33}$ Andrew Chamberlain and Gerald Prante, "Generational Equity: Which Age Groups Pay More Tax, and Which Receive More Government Spending?" Tax Foundation Working Paper No. 156, (2007), p. 1.
} 
Once we take on board the above complications, we need to revise our initial comparison of fiscal impact. While Nora's substantial childhood costs outstrip the costs of Matilda's effective integration into the labour market, admitting Matilda may generate costs associated with fulfilling the social rights of family relatives that she may bring with her. However, the following conclusion seems reasonable: some, though not necessarily all, versions of a replacement migration policy may end up yielding greater fiscally redistributable economic gains for the host state than pronatalism, namely, those versions that focus on admitting skilled and relatively young immigrants and that offer limited family unification provisions. The host state may thus be unable to raise a significant objection against these selective replacement migration policies (as I call will call them from now on).

(iv) The immigrants' home populations. A developed state's demographic policy can also have significant effects on the populations of the immigrant's home state, especially if her home state is a developing state. When skilled workers emigrate from developing states to develop states, their home populations are deprived of the future contributions they might have contributed to their economies. When replacement migration has this so-called "brain drain" effect, it is less preferable to pronatalism from the point of view of the would-be immigrant's home population.

However, according to recent empirical work, a significant number of developing states actually gain economically from skilled emigration. A key factor that explains these so-called "brain gain" cases is the incentive that the possibility of emigration provides for young adults in the developing state to invest in their human capital. Much of the increased stock of human capital that materializes as a result of this incentive ends up 
remaining in the home state (not all skilled individuals emigrate). Emigration can also have positive indirect effects insofar as emigrants transfer knowledge back home. ${ }^{34}$

We should thus qualify the case for replacement migration as follows.

Replacement migration is not normatively preferable to pronatalism in brain drain cases. In such cases, the would-be immigrant's home state may be able to reasonably reject a replacement migration policy, especially considering the fact that, qua population of a developing state, it is already struggling with significant economic and socio-political burdens. Those who remain behind in a brain drain case may have stronger objections to the developed state's prioritising replacement migration than the would-be immigrants amongst them would have to its prioritising pronatalism. Note, however, that the case for

${ }^{34}$ The incentive effect of skilled emigration on human capital formation in some developing states is defended by Michel Beine, Frédéric Docquier and Hillel Rapoport across a number of articles. See especially, "Brain drain and human capital formation in developing countries: winners and losers," The Economic Journal, 118 (2008): 631-652 and "Brain drain and economic growth: theory and evidence," Journal of Development Economics 64 (2001): 275-289. For criticisms of this empirical claim, see Gillian Brock, "Responsibilities In An Unjust World: A Reply to Carens, Kollar, Oberman, and Rapoport," Law, Ethics and Philosophy 4 (2016): 161-182 and Devesh Kapur and John McHale, Give us Your Best and Brightest, (Brookings Institution Press, 2005), Ch. 5. While these criticisms may be forceful against the claim that the incentive effect holds in all cases, my case for replacement migration does not depend on its holding in all cases. I defend replacement migration only in the range of cases in which it has a positive effect on the would-be immigrants' home states. According to Beine et. al. this is not an insignificant number of cases (See "Brain drain and human capital," 644). 
replacement migration will still hold in the range of cases in which skilled emigration produces a brain gain.

The provisional conclusion we should reach is that selective replacement migration policy is normatively preferable to pronatalism in brain gain cases. It would be preferable from the perspectives of would-be immigrants (even assuming tight family unification provisions), and it would not face significant objections from the perspectives of the current populations of the immigrants' host and home state. Furthermore, there is no conclusive reason for thinking that replacement migration is worse from the perspective of future people, both in view of its environment impact and in view of its economic impact, than pronatalism. If replacement migration generates economic gains for current populations and has not done so by increasing public debt, we should assume that it will not make future generations worse off in economic terms than they would have been under pronatalism.

\section{The Cultural Prerogative}

Let me now consider an objection to the priority of replacement migration that rests on considerations of national culture. ${ }^{35}$ The objection begins with the claim that states, like

\footnotetext{
${ }^{35}$ I leave aside two further objections. The first objects that my case for replacement migration "commodifies" immigrants. It does not do that. I appeal to the valuable human capital of immigrants, not in order to justify the claim that the host state ought to benefit from them, but that it has no significant objection to admitting them. The second objection is moved from a global egalitarian perspective and maintains that developed states ought to adopt immigration policies that are more generous than selective replacement migration. This objection also misunderstands my defense: I am defending the priority of selective replacement migration over pronatalism on the non-egalitarian ground that states
} 
individuals, have an agent-centred prerogative to give extra weight to their own interests when deciding between policies. ${ }^{36}$ It then adds that states (or their members) have an interest in preserving a general allegiance in their population to certain values embodied in their national culture. This point, if sound, would favour a prerogative to prioritise pronatalism on the assumption that pronatalism would do better than replacement migration in furnishing future co-citizens who will share an allegiance to the existing national culture of a population. ${ }^{37}$

My response to this objection does not challenge its first claim. Indeed, since my case for replacement migration assumes that the beneficence claims can apply to states as a derivation of beneficence claims that apply to individuals, it must, as a matter of consistency, accept that prerogative claims can apply to states in the same manner. My response focuses, instead, on the objection's second claim, regarding the relevance of the interest in preserving a general allegiance to a national culture. I will argue that we may not regard this interest as a relevant consideration when determining which demographic policy a state must adopt, and that the agent-centred prerogative therefore does not apply. States therefore cannot maintain that they have a prerogative to pronatalise on grounds of national culture.

must undertake relatively costless beneficence. This is compatible with the view that states ought to adopt an immigration policy that is more generous than selective replacement migration on global egalitarian grounds.

${ }^{36}$ The agent-centered prerogative is defended by Samuel Scheffler, The Rejection of Consequentialism (Oxford: Oxford University Press, 1994), Ch. 2.

${ }^{37}$ This assumption may overstate the extent to which native-born generations (in a liberal society) preserve culture (witness the extent to which native-born generations overturned Western culture in the 1960s). 
I begin by distinguishing two views of the value of a general allegiance to a national culture. The first view is that this general allegiance is of intrinsic value: it is valuable for its own sake that there exists a general allegiance to a particular national culture. The second view emphasises only the instrumental value of culture: a general allegiance to a national culture is valuable, on this second view, only insofar as it helps to secure certain further goods for a given population (e.g. it promotes social trust between citizens, and thereby supports the redistributive institutions of the welfare state that supposedly rely on a high degree of social trust). ${ }^{38}$

Consider now the culture based prerogative as it might rest on each of these views in turn. The problem with the intrinsic value version of the prerogative emerges once we notice the following point: how exactly pronatalism and replacement migration will differ in terms of their impact on the preservation of a national culture is something that will depend on what exactly we mean by "national culture". We can usefully distinguish between "thinner" and "thicker" conceptions of national culture. On a thinner conception, national culture consists of a small set of shared abstract beliefs amongst a particular population, say, about how their state's political institutions should function - for example, that they should be democratic in character and that they should respect basic liberal rights. A thin national culture might involve the shared endorsement of a particular political constitution, no more than that. ${ }^{39}$ A thicker conception of national culture, by

\footnotetext{
${ }^{38}$ That shared culture promotes social trust is a claim asserted by David Miller across a number of articles. See, for example, "Immigrants, nations, and citizenship," Journal of Political Philosophy 16 (2008), 371-390.

${ }^{39}$ This is akin to the idea of "constitutional patriotism”. See Jan-Werner Müller and Kim Lane Scheppele, “Constitutional patriotism: an introduction," International Journal of Constitutional Law 6 (2008), 67-71.
} 
contrast, identifies national culture as a dense web of shared specific beliefs about, for example, the value of a particular language, certain norms of social interaction, a particular set of feasts and myths that should be celebrated and re-told from one generation to the next, and a certain interpretation of the historical origins of the existing population. Clearly, the difference in impact that pronatalism and replacement migration will have on the preservation of a "national culture" will be much less significant if we have a thinner rather than thicker conception of it in mind.

The problem with a prerogative based on the intrinsic value of culture can now be stated as follows. Let us grant that pronatalism has more favourable implications than replacement migration for the preservation of a "thick" national culture. Still, we should not take those implications into account in our assessment of demographic policy. There is strong reason for us to reject the view that the state may guide its choice of public policies (including its demographic policies) on the basis of one or another conception of the intrinsic value of a thick national culture. This is because different members of the host population can reasonably disagree about the kind of national culture that is intrinsically valuable, and there are weighty reasons to avoid establishing any particular view about how their disagreement should be resolved. Some may believe that other members of their society should share a general allegiance only to a political constitution, and indeed that it is to be regretted if a thicker national culture should emerge beyond that. Others may believe it is valuable that their society should consist of a culturally more cohesive population. While it is reasonable that each side in this disagreement should promote their own view of this matter by exercising their freedom of speech, it is not reasonable, at least in a liberal-democratic state, for either side to use the apparatus of the state to coercively promote their view (e.g. by taxing people in order to fund a pronatalist policy). This would be a failure to take seriously the idea that state policies - including demographic policies must be justified to citizens who reasonably disagree about what makes life valuable, 
including the kind of national culture that people should be able to participate in. Note, that my claim, here, is not that a pro-immigration policy, rather than an anti-immigration policy, should be adopted as matter of default. I am making the more limited claim that a certain consideration may not be appealed to by citizens when they deliberate over demographic policy, namely, that a particular conception of national culture should be coercively promoted in a context in which people reasonably disagree about the kind of national culture that is valuable. ${ }^{40}$ A state prerogative to pronatalise cannot therefore be justified by appealing to the intrinsic value of national culture.

Consider, next, a prerogative based on the instrumental value of national culture. This prerogative seems more defensible because the claim that the goods of social trust and economic solidarity (for which it says a shared national culture is necessary) are worth protecting is not as controversial as the claim that a particular thick conception of national culture is intrinsically valuable. However, there are two problems with the instrumental cultural prerogative. First, it is far from clear that cultural diversity actually undermines social trust. Anti-immigration platforms have indeed been on the rise in many states today and have played significant roles, for example, in the Brexit referendum, and in recent US,

${ }^{40}$ For a defence of the idea that political institutions may not promote a particular conception of national culture on the ground that it is intrinsically valuable, see Ronald Dworkin, Sovereign Virtue (Cambridge, MA: Harvard University Press, 2000), pp. 212215. The point I am making in this paragraph can also be moved from within the political liberalism of John Rawls, according to which political institutions must restrict their policies to those that can be justified on the basis of "public reason". Arguably, the view that citizens must comply with the requirements of a controversial conception of national culture fails that test. See John Rawls, Political Liberalism (New York: Columbia University Press, 2005), pp. 212-254. 
Austrian, Dutch, French and German elections. But it would be a knee-jerk reaction to infer from these developments that cultural diversity per se undermines social trust. First, a broader view of the empirical evidence does not warrant such an inference. As Will Kymlicka writes, there are now "hundreds of studies", and several meta-analyses of empirical research, that suggests that the claim that cultural diversity increases social distrust is inconclusive. ${ }^{41}$ Secondly, the nature of the impact that cultural diversity has on social trust is likely to be mediated by state policies that form the background against which members of a culturally diverse population interact with each other. ${ }^{42}$ For example, the effects of cultural diversity on social trust may vary depending on whether the state uses means-tested or unconditional welfare programs (means-tested welfare programs may reduce levels of social trust in the context of cultural diversity, because they may encourage the perception that recipients who belong to other cultures are "gaming" the system state by misreporting their economic status). ${ }^{43}$ The effects of cultural diversity on social trust may also be influenced by the different ways in which the state integrates immigrants into its native population. So, to summarise, while the intrinsic version of the cultural prerogative should be ruled out of bounds, the instrumental version is inconclusive. Neither thus stands in the way of the other considerations discussed in the preceding part of the article, which justify the priority for replacement migration.

\footnotetext{
${ }^{41}$ See Kymlicka, "Solidarity in diverse societies: beyond neoliberal multiculturalism and welfare chauvinism," Comparative Migration Studies 3 (2015). https://doi.org/10.1186/s40878-015-0017-4

${ }^{42}$ For an elaboration, see Ryan Pevnick, "Social trust and the ethics of immigration policy, Journal of Political Philosophy 17 (2009), 146-167.

${ }^{43}$ See Bo Rothstein, Just Institutions Matter (Cambridge: Cambridge University Press,
} 1998). 


\section{Conclusion}

My aim has not been to determine how developed states should strike the balance between non-demographic and demographic policies in response to their ageing populations but the moral merits of two demographic policies. My conclusion is that developed states must prioritise selective replacement migration over pronatalism, at least in circumstances in which selective replacement migration produces a brain gain for developing states. This conclusion does not rest on the assumption that states have a duty to eliminate or reduce global inequality but on the more modest assumption that states ought to adopt policies that provide significant benefits to non-members when they (or others) would not incur significant costs in their doing so. This conclusion also rests on a number of provisional empirical claims that I have made. I have given reason for why these empirical claims are plausible, but they have not been tested.'The case for replacement migration I have made is thus best seen as a working hypothesis about the kind of demographic policy developed states ought to adopt (should they adopt a demographic policy at all), and as setting the direction for the empirical research we would need to pursue in order to arrive at a more final view of that matter. 